\title{
Is it Computer Literacy, IT, ICT or Informatics?
}

\author{
What is going on in Austria's Compulsory Schools in the \\ Context of Educational Standards?
}

\author{
Peter Micheuz \\ University of Klagenfurt, Institut für Informatik-Systeme \\ Universitätsstraße 65, 9020 Klagenfurt, Austria \\ peter.micheuz@uni-klu.ac.at
}

\begin{abstract}
Schools in Austria providing compulsory education are accountable for imparting IT skills and informatics competencies to their pupils. The term and subject "informatics" encompasses almost every activity which has to do with computers at schools. In many cases "IT" would be more appropriate to describe the present situation at the lower secondary level. Therefore clarity of the terms "IT" and "Informatics" is necessary. This paper also addresses the issue of developing educational standards in that field, which are considered important to close the digital gap after compulsory education.
\end{abstract}

\section{Introduction}

Without doubt the information and knowledge society exerts an enormous influence on education at all levels of schools. This applies not only to vocational schools but also to schools imparting general education. The Austrian school system encompasses the elementary (grades 1 to 4), lower secondary (grades 5-8) and upper secondary levels (grades 9-12/13). This paper mainly deals with the approaches of establishing IT/informatics in secondary education in Austria with respect to the compulsory grades 5 to 9 .

Beginning in the early nineties of the last century, the subject "informatics" has been implemented at the secondary lower level for pupils aged 10 to 14 years in various forms. Presently there are only a few lower secondary schools which offer the subject informatics continuously. Until now the lower secondary level in Austria 
must be seen as a patchwork with regard to an overall systematic supply of IT/informatics knowledge and skills.

\section{IT/informatics as a part of general education}

It is obvious that information technology has dramatically changed the world outside our schools and is changing the teaching and learning environment within them. The survey "Key data on ICT in schools in Europe" reveals that at the age of 15 a majority of European pupils claim to use computers at school regularly. But the PISA study [11] shows that the regularity of using the computer in school activities is still very heterogeneous across all investigated countries. While in some countries about two-thirds of the 15-year-old pupils use computers at schools once or several times a month, there are enormous differences between countries, between the schools within a country, and even between classes or groups within schools.

Mastering of the common language, applying mathematical modeling, being competent in at least one foreign language, the self regulation of acquisition of knowledge, and last but not least IT-competencies are regarded as basic cultural tools [1]. Thinking of a new and widely-accepted contemporary canon of education, we cannot ignore this. Informatics as the basic and referring science of ICT can therefore be considered indispensable in every educational process. Many countries today consider understanding ICT and mastering basic skills and concepts of ICT as part of the core of education, alongside reading, writing and numeracy [6].

Since 1985 when the subject informatics was implemented in all Austrian secondary academic schools in grade 9 , this term has been frequently in use and a quasi placeholder for everything which has to do with computers. The artificial term "informatics", deduced from "information" and "automation/automatics" has its origin in Europe, but it is not in frequent use in other parts of the world.

A survey in [4] shows the trend for an integrated approach using ICT. In some countries, ICT is part of the compulsory minimum curriculum. Official recommendations regarding these approaches are fairly similar among the countries. Among the official aims of the curriculum, activities involving the use of software, information searches and communication networks for extending knowledge of various subjects are uniformly the most representative, irrespective of the level concerned in compulsory education. In many countries, the amount of time set aside for ICT is very flexible. Only in a few countries, and particularly in those of central and eastern Europe, is there a minimum annual number of hours to be marked for teaching ICT as a separate subject. Whereas ICT is the common term in most European countries, in Austria it is called "informatics".

ICT is one side of the coin, informatics the other. "Does ICT eat or feed informatics" was the topic of a noteworthy panel discussion held at the ISSEP conference in March 2005 in Klagenfurt (http://issep.uni-klu.ac.at), which as expected did not lead to a clear conclusion. The borders cannot be drawn exactly. They are fairly indistinct and floating. But Table 1 below should provide more clarification and moves informatics definitively towards general education with a certain degree of product independency and conceptual knowledge. 
Table 5. A Comparison reflecting the Difference between IT and Informatics

\begin{tabular}{ll}
\hline IT & Informatics \\
\hline specific education & general education \\
concrete, practical & abstract, theoretical \\
application oriented & fundamental, basal \\
instruction, training & education \\
technical schooling, courses & class, lessons \\
Certificates & school reports \\
product knowledge & conceptual knowledge \\
Just in time and short term learning & sustainability \\
instantly available knowledge & general knowledge \\
using software & modeling and developing software \\
applying software & reflecting the use of Informatics systems \\
competencies, skills & knowledge, comprehension \\
executing tasks & problem solving \\
\hline
\end{tabular}

This dichotomy, with the (job) training on the left side and the alleged (academic) "ivory tower" on the right side, still leaves one major concern: the distinction between "pure" informatics (or is it computer science?) and applied informatics (IT, ICT) also troubles secondary education. While other science, technology, engineering and math disciplines have improved their diversity of terms in the last years, ours has gotten significantly worse.

\section{Global frameworks, definitions and approaches}

The importance of IT/informatics education is not only restricted to Austria, Germany and the rest of Europe. Global initiatives to establish frameworks for IT/informatics curricula for all stages prove to be a worldwide concern and can be identified in the form of proposals from very prominent institutions such as UNESCO/ IFIP, ISTE and the ACM.

Ludger Humbert [3] stresses the importance of reinforced international networking in the field of informatics in schools. At the same time he complains that the acquisition of IT skills is primary and dominating too much at the expense of a deeper reflection and concepts of informatics.

It is remarkable but not surprising that the task force around Tom van Weert [10] decided to use the uniform denotation "ICT" instead of "computer science". Here ICT is used, applied and integrated in all activities of working and learning on the basis of conceptual understanding and methods of informatics. This framework is based on the definition "ICT by methods of informatics". In order to enrich the discussion about terminology regarding the buzzword "e-literacy", definitions for "computer literacy" [2], informatics literacy [3] or "ICT lieracy" [6] can be found.

Moreover, the UNESCO/IFIP paper [10] defines "informatics" as the science dealing with the design, realization, evaluation, use, and maintenance of information processing systems, including hardware, software, organizational and human aspects, and the industrial, commercial, governmental and political implications of these". 


\section{About curricula, the ECDL and educational standards}

In Austria and also Germany a remarkable debate on curricula is going on. Obviously, curricula do not have the expected impact on the outcomes of the pupils. The emerging buzzword in this context is "educational standards". Obviously, these standards aim at the crucial part of the curriculum, namely the definition of its objectives which are often expressed in terms of learning outcomes.

The recent PISA-study of 2003 [11] revealed some obvious deficits of Austrian pupils in the area of math and problem solving, so that the Ministry of Education immediately reacted to that situation in establishing the shift from input orientation to output measurement in the form of educational standards.

Due to Austria's rather disappointing ranking in the recent PISA-study 2003, educational standards are developed for the subjects German, English and maths. Independent of these activities, since 1998 a remarkable development in the Austrian educational system with regard to IT education has taken place. Under the patronage of the Ministry of Education, the European Computer Driving License [12] plays a prominent role in the Austrian school system. The ECDL certificate is offered at all stages of secondary education, and some schools even adopt the ECDL core syllabus as the basis of the subject "informatics". This is unique in Europe. The syllabus of the ECDL consists of seven modules and matches exactly with the proposed framework in [10] except for modules on ethical issues and jobs and/with ICT.

When speaking of basic IT-skills, one cannot ignore the ECDL. The ECDL with its global extension ICDL (International Computer Driving License) is available in about 140 countries worldwide. At the moment it is the world's leading and largest vendor-neutral end-user computer skills certification program with presently almost 6 million participants. Although the Austrian model of the ECDL in schools can doubtlessly be considered successful, there is concern that it is not an appropriate educational standard for general education. Therefore the Austrian ministry for education is at the point of developing educational standards also in the field of informatics. This initiative aims at a more comprehensive understanding of informatics beyond mere IT product training. Even if these ambitious educational standards should be established, there would be a long road to acceptance.

However, the prospects of realizing these educational standards seem to be promising because the development of ICT literacy as a new assessment domain of PISA has been considered relevant [5]. The development of widely-accepted and output-oriented educational standards could help bridge the obvious gap between IT and informatics and may address the demands from policy makers and the informatics community as well. As a consequence, within their autonomy Austrian schools would have to take appropriate measures to establish an increasing number of informatics classes and/or provide better integration of informatics into other subjects. At present e-learning activities in Austria's schools are noticeable and increase the need for IT competencies grounded in a profound informatics education.

\section{Conclusion}

We still experience an annoyingly diffuse use of terminology such as "computer literacy", "IT", "ICT", "computer science" or the preferable middle/eastern 
European term "informatics", which in Austria holds for almost every activity with computers. Standardizing the terminology would be a worthwhile global task.

Lower secondary education can still be regarded as at an important stage with respect to IT/Informatics education. Due to the fact that not all pupils in Austrian schools experience the first systematic instruction in IT/informatics, the digital gap is still undesirably wide at this level. Standardizing the learning objectives in the form of educational standards as extended curricula with the focus on output measurement could improve this situation. The certificate ECDL/ICDL, which is offered and accepted at lower secondary schools in Austria, is not compulsory and due to autonomy it does not reach the majority of pupils.

Educational standards for informatics in addition to the quasi-standard ECDL/ICDL are presently developed by formal and informal working groups [13]. In the view of many informatics teachers this is regarded as a necessary process. The result in the form of obligatory learning objectives and appropriate assignments should guarantee that a vast majority of pupils aged 15 will not only dispose of basic IT skills and ephemeral software handling. A deeper understanding of informatics, accompanied by more creativity, problem solving and reflection would be very much appreciated also at the lower secondary level.

\section{References}

1. Baumert J., in Die Zukunft der Bildung. N Kilius et al. Eds., Suhrkamp, Frankfurt, 2003.

2. Bork A. M., Personal Computers for education, New York, Harper \& Row, 1985.

3. Humbert L., Didaktik der Informatik, Teubner, Wiesbaden, 2005.

4. Key Data on ICT in Schools Eurydice, Brussels, 2004.

5. Kirsch I. et al., Feasibility Study for the ICT Literacy Assessment, PISA, October 2003.

6. Maarten van Veen, Fed Mulder, Karle Lemmen, What is lacking in Curriculum Schemes for Computing / Informatics? In Proceeding for the SIGCSE conference 2004, Leeds.

7. Marsh C.J., and Willis G., Curriculum: Alternative Approaches, 1999

8. Reiter A., Micheuz P. eds,, CDA - Sonderausgaben bm:bwk, CDA-Verlag, Linz, 2005.

9. Weiß P. et al., ICT-Skills Certification in Europe, found at http://www.cepis.org/download.

10. Weert, van T. UNESCO, ICT in Education, Paris, 2002.

11. http://www. pisa.oecd.org, PISA G.B. 3-5 Oct.2005, Iceland [proved 15.1.2006].

12. http://www.ecdl.at [proved 15.1.2006].

13. http://www.schulinformatik.at [proved 15.1.2006]. 